Communication

\title{
Linking Population and Forest Dynamics over the Conterminous US for the 1990s and 2000s
}

\author{
Giorgos Mountrakis *, Sheng Yang
}

State University of New York College of Environmental Science and Forestry, 1 Forestry Dr., Syracuse, NY, 130210, USA; E-Mails: gmountrakis@esf.edu; syang16@syr.edu

* Correspondence: Giorgos Mountrakis; E-Mail: gmountrakis@esf.edu

Academic Editor: Zed Rengel

Adv Environ Eng Res

2021, volume 2, issue 1

doi:10.21926/aeer.2101003
Received: September 24, 2020

Accepted: March 03, 2021

Published: March 09, 2021

\begin{abstract}
Few studies have investigated deforestation and population connections in the U.S. at large spatial extents or small scales. We examined forest cover changes over two decades, 19902000 and 2000-2010, in the continental U.S. at the county scale. Forest dynamics were estimated using the National Land Cover Database, a satellite-derived classification product and then linked to population data from the US. Census. At the aggregate level, high population growth seems to increase net forest loss in a non-linear manner, especially in the 2000s. Counties were also ranked based on observed forest change when compared to counties of similar population change. Looking specifically at the county level, the majority of counties with low ranking (interpreted as disproportionate high forest loss for experienced population change) were in the south east region for both 1990s and 2000s. In 2000s, the entire east coast demonstrated low rankings, along with regions in the northwest (Oregon and Washington) and central north (Minnesota, northern Wisconsin/Michigan). While our study was not designed to group socioeconomic and environmental drivers, linking forest dynamics to population changes offers important insights and supports comparisons at the national scale. Future work should consider targeted regional analysis motivated by our results and multi-factor modeling.
\end{abstract}

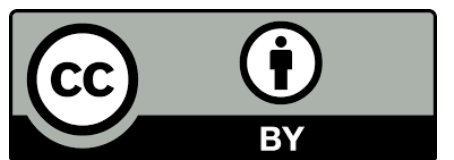

(C) 2021 by the author. This is an open access article distributed under the conditions of the Creative Commons by Attribution License, which permits unrestricted use, distribution, and reproduction in any medium or format, provided the original work is correctly cited. 


\section{Keywords}

Deforestation; population growth; national scale; U.S.

\section{Introduction}

Deforestation, the removal of forests and subsequent conversion to other land cover/use, has considerable impact on forest ecosystem functions and services, including biodiversity [1-3], carbon cycle and climate [4, 5], water purification [5, 6], and nutrient cycling [7]. In light of the critical role of forests and increasing deforestation due to climate change and economic growth, numerous studies have focused on deforestation and forest cover change monitoring [8-10].

Within the U.S. forest changes have been monitored through the recent proliferation of satellitederived forest cover datasets [11-13]. In addition, recent studies have shown pervasive deforestation across the conterminous U.S. [14-17]. For example, it has been found that collectively forest cover experienced the largest net decline of 97,000 km2 including lands in a temporarily disturbed state among all land cover classes between 1973 and $2000-25,000 \mathrm{~km}^{2}$ of the forest cover loss was converted to agriculture and development [14]. In another study, using the national land cover retrofit change product 1992-2001, forest area changes between 1992 and 2001 were reported at U.S. state levels. There the deforestation rate in protected areas was lower than unprotected lands [18].

Urbanization and population growth as well as proximity to residential areas have been recognized as major factors of forest cover loss [19-21]. Forest cover loss in the U.S. is closely related to urban development and subsequent land use changes [17, 18, 22] with over $40 \%$ of urban development coming from forest cover changes in many U.S. regions [16]. Population in the U.S. is projected to increase in the first half of twenty first century, resulting in increased residential area and deforestation [22]. A significant limitation of forest cover loss studies across the U.S. was either their localized extend of their coarse spatial scale (major ecoregions). This study aims to bridge this gap through a comparative analysis of forest/population dynamics at the continental U.S. from the 1990 s to the 2000s.

\section{Materials and Methods}

Our study area was the conterminous U.S. and the analysis was conducted at the county geographic level. Two decades were contrasted by comparing the 1990s with the 2000s. Forest cover data were obtained from the National Land Cover Database (NLCD) change product of 19922001 and the 2011 NLCD product. Both provide satellite-derived and wall-to-wall forest cover datasets covering the continental U.S. The change product of 1992-2001 has over $80 \%$ accuracy for forest cover changes [8]. In a more recent accuracy assessment including 2001 and 2011 NLCD, the user's accuracies for estimating forest loss was near $80 \%$ for the period [23]. While this $80 \%$ accuracy is not ideal we do not expect any bias introduced in our analysis considering that forest changes are aggregated at the county level from the $30 \mathrm{~m}$ NLCD product. To create forest binary maps, several NLCD classes were merged together into a single forest class. These classes included the deciduous forest, evergreen forest, and mixed forest; these three classes were combined as the 
general category of forest without considering specific forest types. We should note that we analyzed the total (net) forest change, that is the combined effect of gains and losses within a county. We generated net forest cover change by county using zonal statistics to show overall magnitude and direction of forest dynamics in the two decades. Forest changes reported in this study can be different from other data, e.g., Forest Inventory Analysis (FIA) data because the definition of forest in NLCD is based on land cover, but the definition of forest in FIA data is based mainly on forest land use.

The forest cover observations were matched with corresponding population estimates obtained from three decadal Census data from 1990, 2000, and 2010. Population data were extracted from the National Historical Geographic Information System (NHGIS) database of the Minnesota Population Center (www.nhgis.org). Percentage population changes were also computed for the two decades.

Both forest cover and population data were aggregated at the county level. From the original 3,109 counties 23 were removed as they were newly-added, deleted, or divided during the two decades of 1990s and 2000s, reducing the number of counties to 3,086. Counties that changed names during the two decades were able to be matched based on consistent locations and boundaries. Finally, counties with forest cover less than 10\% in both 1992 and 2001 were removed to prevent influence from low forest density. This produced the final count of 2,132 counties that were kept in the subsequent analysis. The final forest cover map of the 2,132 from 2001 NLCD data is shown in Figure 1.

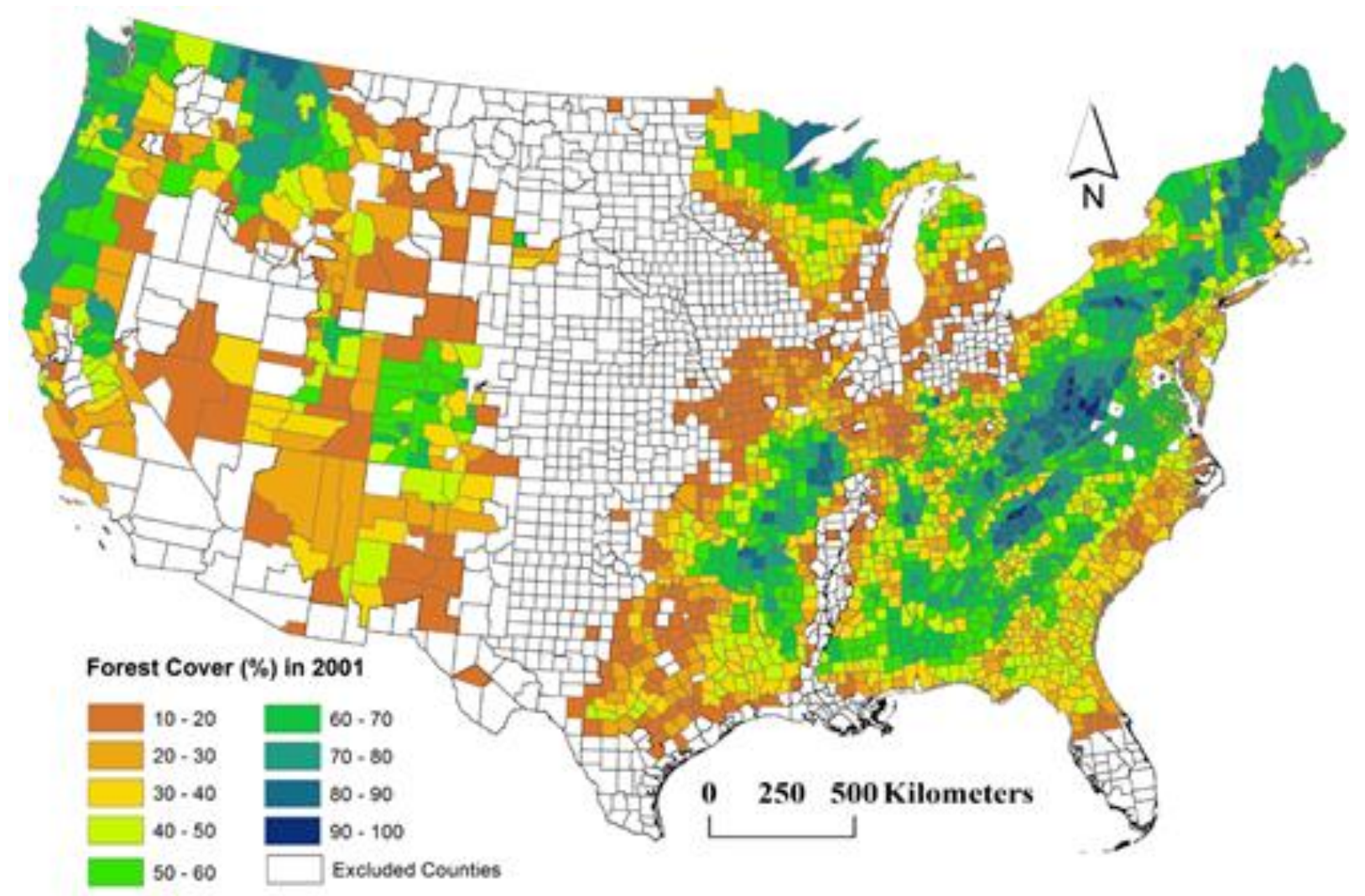

Figure 1 Forest cover from 2001. Data extracted from the NCLD change product and aggregated at the county level. 


\section{Results and Discussion}

Population and forest dynamics were first examined by creating boxplots of each of the two decades (Figure 2). Each box expresses the 5\% and 95\% outer limits with the inner boxes depicting the $25 \%$ and $75 \%$ values and the center line showing the median value. While the population growth pressure on forest loss is evident across both decades (right side of the graph), it is considerably accelerated for the 2000s and especially for counties that have experienced high population growth. Another interesting observation comes from the number of counties belonging in every bin (presented at the top of the graph). The counties from the 1990s experiencing high population growth (right four bins) are approximately double the corresponding counties from the 2000s. This leads us to conclude that while extreme population growth was more subdued in the 2000s (and/or wider distributed at the county level), it came at a much larger expense in terms of forest encroachment. This is also backed up by U.S. Census data that indicate a population growth of approximately $33 \mathrm{M}$ people for the 1990 s compared to $27 \mathrm{M}$ people for the 2000 s.

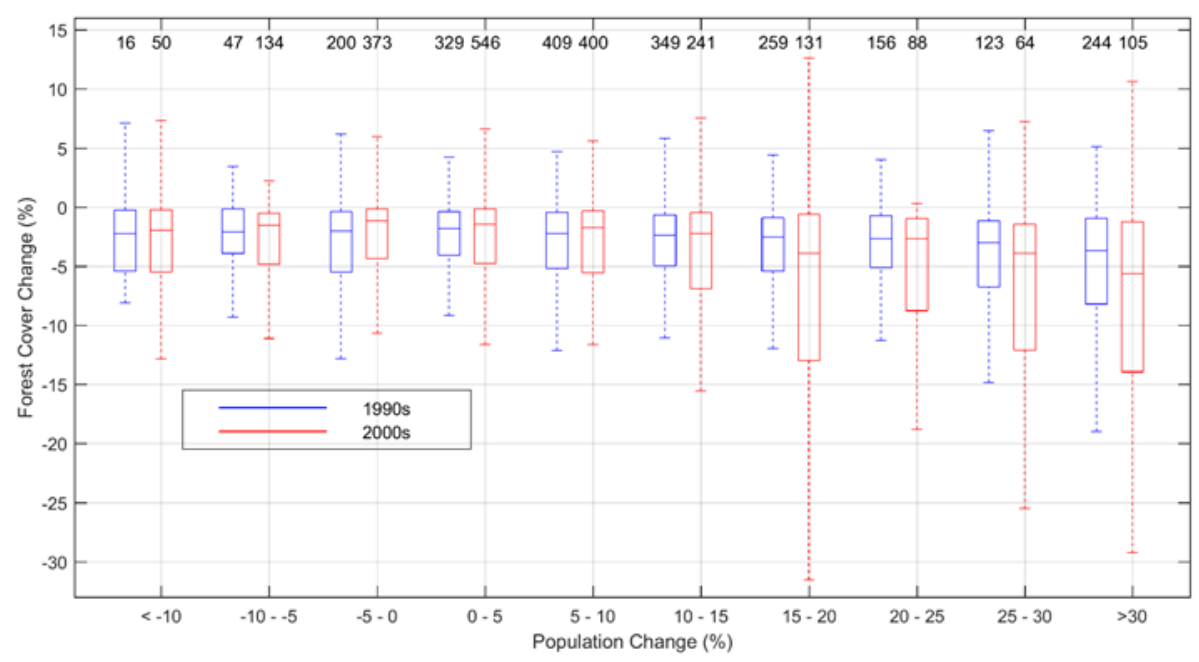

Figure 2 Relationship between population and net forest cover change in 1990s and 2000s. The numbers above boxplots represent county totals in each group of population percentage change in the two decades.

The boxplot analysis aggregates counties to offer a concise national viewpoint. The second part of our analysis was motivated by identification of county-specific behavior, thus allowing more detailed insights and management adjustments. Each bin in figure two contains the number of counties presented at the top of the figure. A relative ranking took place separately for each bin. For example, if a county from the 1990s fell into the 0\%-5\% population change (fourth blue bin from the left), then its ranking was contrasted to the other 408 counties belonging in the same bin and a percentile in terms of forest cover change was assigned.

Counties were assigned to one of six groups corresponding to percentiles of $10^{\text {th }}, 25^{\text {th }}, 50^{\text {th }}, 75^{\text {th }}$, and $90^{\text {th }}$ of distribution of net forest cover changes within their group. A lower ranking for a given county indicated a higher forest loss when contrasted with counties of similar population change. In other words, the higher ranked counties experienced less forest loss (or in a few cases higher gain) again when contrasted with the peer group of population change. 
The majority of counties with low ranking were in the southeast region in both the 1990s and 2000s (Figure 3). These persistent southeast low rankings are probably driven by high harvesting [12]. Specifically, in Eastern Temperate Forests Level I ecoregion covering Southeast and Eastern coast areas, logging, agriculture, and development are the major types of gross forest losses from 1973 to 2000 [14]. The economic recovery in the second half of 1980s stimulated additional new construction, and by 2000 the southern ecoregions had become the most important commercial forest region across U.S.

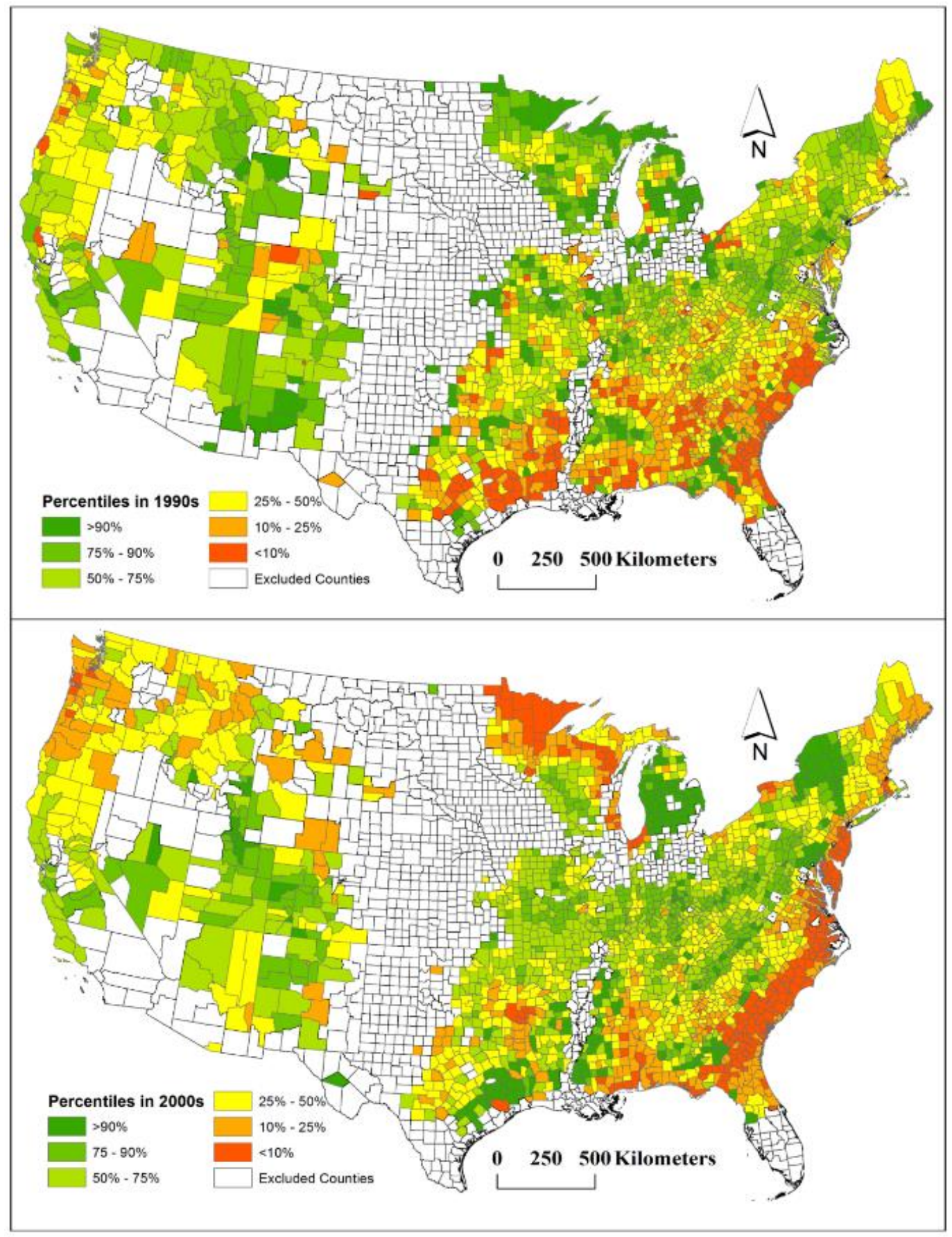

Figure 3 Relative ranking of net forest cover changes among U.S. counties with similar population changes. Lower rankings (smaller percentiles) represent higher proportional forest cover loss. 
In the 2000s a shift is observed, where reduction in Texas, Louisiana and Arkansas was replaced by a further northwardly encroachment along the entire east coast. Coupled with higher rankings in northwest (Oregon and Washington) and a few other isolated spots (e.g. Buffalo and Rochester in NY) the urbanization effect is clearly identifiable. Our observations are consistent with other local studies, for example Lo and Yang [24] identified similar patterns in the Atlanta area (ranking less than $10 \%$ for Atlanta-containing Fulton County in Georgia). Higher rankings in the 2000s were also observed in Minnesota and northern Wisconsin/Michigan. While population dynamics may have played a role, the majority of this ranking is potentially caused by forest disturbances such as insects, diseases, and drought [14].

To conclude, there is a wide range of drivers behind forest dynamics, mostly operating at the local and regional scales. While our study was not designed to separate these drivers, linking forest dynamics to population changes offers important insights and supports comparisons at the national scale, a currently important but missing piece of the puzzle. Future work should concentrate on regional analysis motivated by our results and link socioeconomic and environmental factors to help tease out local drivers, for example forest harvesting, drought, disease, fire, and agricultural pressures.

\section{Author Contributions}

Mountrakis designed the experiment and wrote the manuscript. Yang conducted the experiment and produced the figures.

\section{Funding}

This work was supported by the National Urban and Community Forestry Advisory Council, U.S. Forest Service and a SUNY ESF Graduate Assistantship.

\section{Competing Interests}

The authors have declared that no competing interests exist.

\section{References}

1. Lovejoy TE, Bierregaard Jr RO, Rylands AB, Malcolm JR, Quintela CE, Harper LH, et al. Edge and other effects of isolation on Amazon forest fragments. In Conservation biology: The science of scarcity and diversity. Cambridge, MA: Cambridge University Press; 1986.

2. Jarzyna MA, Porter WF, Maurer BA, Zuckerberg B, Finley AO. Landscape fragmentation affects responses of avian communities to climate change. Glob Chang Biol. 2015; 21: 2942-2953.

3. Colwell RK, Brehm G, Cardelús CL, Gilman AC, Longino JT. Global warming, elevational range shifts, and lowland biotic attrition in the wet tropics. Science. 2008; 322: 258-261.

4. Houghton RA, Hackler JL. Changes in terrestrial carbon storage in the United States. 1: The roles of agriculture and forestry. Glob Ecol Biogeogr. 2000; 9: 125-144.

5. Harris NL, Hagen SC, Saatchi SS, Pearson TR, Woodall CW, Domke GM, et al. Attribution of net carbon change by disturbance type across forest lands of the conterminous United States. Carbon Balance Manag. 2016; 11: 24. 
6. Howarth RW, Billen G, Swaney D, Townsend A, Jaworski N, Lajtha K, et al. Regional nitrogen budgets and riverine $N \& P$ fluxes for the drainages to the North Atlantic Ocean: Natural and human influences. In Nitrogen cycling in the North Atlantic Ocean and Its Watersheds. Switzerland: Biogeochemistry; 1996. pp. 75-139.

7. McLauchlan KK, Craine JM, Oswald WW, Leavitt PR, Likens GE. Changes in nitrogen cycling during the past century in a northern hardwood forest. Proc Natl Acad Sci U S A. 2007; 104: 7466-7470.

8. Kim DH, Sexton JO, Noojipady P, Huang C, Anand A, Channan S, et al. Global, Landsat-based forest-cover change from 1990 to 2000. Remote Sens Environ. 2014; 155: 178-193.

9. Riitters K, Wickham J, Costanza JK, Vogt P. A global evaluation of forest interior area dynamics using tree cover data from 2000 to 2012. Landsc Ecol. 2016; 31: 137-148.

10. Hansen MC, Potapov PV, Moore R, Hancher M, Turubanova SA, Tyukavina A, et al. Highresolution global maps of 21st-century forest cover change. Science. 2013; 342: 850-853.

11. Soulard CE, Acevedo W, Cohen WB, Yang Z, Stehman SV, Taylor JL. Harmonization of forest disturbance datasets of the conterminous USA from 1986 to 2011. Environ Monit Assess. 2017; 189: 170.

12. Cohen WB, Yang Z, Stehman SV, Schroeder TA, Bell DM, Masek JG, et al. Forest disturbance across the conterminous United States from 1985-2012: The emerging dominance of forest decline. For Ecol Manag. 2016; 360: 242-252.

13. Masek JG, Goward SN, Kennedy RE, Cohen WB, Moisen GG, Schleeweis K, et al. United States forest disturbance trends observed using Landsat time series. Ecosystems. 2013; 16: 1087-1104.

14. Sleeter BM, Sohl TL, Loveland TR, Auch RF, Acevedo W, Drummond MA, et al. Land-cover change in the conterminous United States from 1973 to 2000. Glob Environ Change. 2013; 23: 733-748.

15. Yang $S$, Mountrakis G. Forest dynamics in the US indicate disproportionate attrition in western forests, rural areas and public lands. PloS ONE. 2017; 12: e0171383.

16. Auch RF, Drummond MA, Xian G, Sayler KL, Acevedo W, Taylor JL. Regional differences in upland forest to developed (Urban) land cover conversions in the conterminous US, 1973-2011. Forests. 2016; 7: 132.

17. Drummond MA, Loveland TR. Land-use pressure and a transition to forest-cover loss in the eastern United States. BioScience. 2010; 60: 286-298.

18. Zheng D, Heath LS, Ducey MJ. Carbon benefits from protected areas in the conterminous United States. Carbon Balance Manag. 2013; 8: 4.

19. Boucher D, Elias P, Lininger K, May-Tobin C, Roquemore S, Saxon E. The root of the problem: What's driving tropical deforestation today? Cambridge, MA: Union of Concerned Scientists; $2011 ; 20113229372$.

20. DeFries RS, Rudel T, Uriarte M, Hansen M. Deforestation driven by urban population growth and agricultural trade in the twenty-first century. Nat Geosci. 2010; 3: 178-181.

21. Schneider LC, Pontius Jr RG. Modeling land-use change in the Ipswich watershed, Massachusetts, USA. Agric Ecosyst Environ. 2001; 85: 83-94.

22. Alig RJ, Plantinga AJ, Ahn SE, Kline JD. Land use changes involving forestry in the United States: 1952 to 1997, with projections to 2050. Portland, OR: US Department of Agriculture, Forest Service, Pacific Northwest Research Station; 2003; PNW-GTR-587. 
23. Wickham J, Stehman SV, Gass L, Dewitz JA, Sorenson DG, Granneman BJ, et al. Thematic accuracy assessment of the 2011 national land cover database (NLCD). Remote Sens Environ. 2017; 191: 328-341.

24. Lo CP, Yang X. Drivers of land-use/land-cover changes and dynamic modeling for the Atlanta, Georgia metropolitan area. Photogramm Eng Remote Sensing. 2002; 68: 1073-1082.

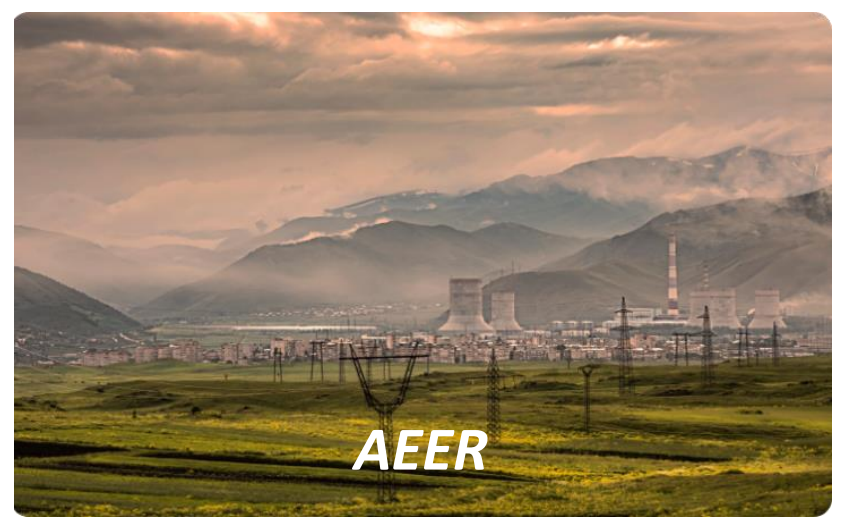

Enjoy $A E E R$ by:

1. Submitting a manuscript

2. Joining in volunteer reviewer bank

3. Joining Editorial Board

4. Guest editing a special issue

For more details, please visit:

http://www.lidsen.com/journals/aeer 